Disponível em:

http://editora.unoesc.edu.br/index.php/race

RACE, Joaçaba, v. 17, n. 1, p. 197-224, jan./abr. 2018

\title{
IMPACTOS DA OFERTA PÚBLICA INICIAL DE AÇÕES NO DESEMPENHO ECONÔMICO-FINANCEIRO DE EMPRESAS
} BRASILEIRAS NA B3

\author{
Impacts of the initial public offer of shares in economic and financial performance of \\ brazilian companies in $\mathrm{B} 3$
}

João Paulo Albuquerque Kalil

E-mail: albuquerquekalil@hotmail.com

Mestre em Administração pela Universidade Federal de Lavras; Especialista em MBA Gestão Estratégica de Finanças pela Universidade Federal de São João Del-Rei; Professor de Administração/Gestão no Instituto Federal de Tecnologia - Campus Santos Dumont. Endereço para contato: Rua Técnico Panamá, 45, Quarto Depósito, 36240-000, Santos Dumont, Minas Gerais, Brasil.

Gideon Carvalho de Benedicto

E-mail: gideon.benedicto@dae.ufla.br Doutor em Controladoria e Contabilidade pela Universidade de São Paulo; Mestre em Ciências Contábeis e Atuariais pela Pontifícia Universidade Católica de São Paulo; Professor Associado no Departamento de Administração e Economia da

Universidade Federal de Lavras. 


\section{Resumo}

Neste artigo objetivou-se discutir os impactos do Initial Public Offering (IPO) no desempenho econômico-financeiro de empresas brasileiras listadas na B3. Esses impactos foram analisados em termos de: crescimento das vendas, rentabilidade dos ativos, rentabilidade do patrimônio líquido e lucratividade das vendas. Para alcançar os objetivos, foi utilizada a base de dados das empresas que realizaram IPO no período de 2008 a 2013. Na pesquisa apresentaram-se fundamentos teóricos e informações advindas de pesquisas e instituições compreendendo revisão da literatura, temas relativos às decisões de financiamento, oferta pública inicial de ações e desempenho econômico-financeiro de empresas por meio de indicadores. A metodologia, de forma geral, tratou-se de pesquisa explicativa e quantitativa. As demonstrações financeiras foram coletadas por meio dos relatórios financeiros disponíveis no site de cada empresa e também no site da B3. A amostra final contemplou 28 empresas de diversos tamanhos e setores. Mais especificamente, foi utilizada metodologia de estatística multivariada com modelos econométricos de regressão linear múltipla em dados em painel. Com base nessa discussão, os resultados encontrados sugerem que a realização do IPO gerou impacto positivo no crescimento das receitas líquidas de vendas. Por outro lado, o IPO resultou em impacto negativo no desempenho das empresas em termos de rentabilidade dos ativos e patrimônio líquido. Por fim, a variável IPO não apresentou significância no modelo de lucratividade das vendas medida pela margem líquida.

Palavras-chave: Decisões de financiamento. Mercado de capitais. IPO. Desempenho de empresas.

\section{Abstract}

The article aimed to discuss the impacts of the IPO on the economic-financial performance of Brazilian companies listed in B3. These impacts were analyzed in terms of: sales growth; profitability of assets; return on shareholders' equity; and profitability of sales. In order to reach the objectives, the database of the companies that carried out the IPO between 2008 and 2013 was used. The research presented theoretical foundations and information from researches and institutions, including literature review, financing decisions, initial public offering of stock and economic-financial performance of companies through indicators. The methodology, in general, was an explicative and quantitative research. The financial statements were collected through the financial reports available on each company's website and also on the B3 website. The final sample included 28 companies of different sizes and sectors. More specifically, a multivariate statistical methodology was used with multiple linear regression econometric models in panel data. Based on this discussion, the results suggest that the IPO generated a positive impact on the growth of net sales revenues. On the other hand, the IPO resulted in a negative impact on the performance of companies in terms of the profitability 
of assets and shareholders' equity. Finally, the IPO variable was not significant in the sales profitability model measured by the net margin.

Keywords: Financing decisions. Capital market. IPO. Performance of companies.

\section{INTRODUÇÃO}

A decisão sobre a composição do capital da empresa é importante no mundo das finanças. A estrutura de capital, com definição do volume de capital próprio e de terceiros na empresa deve ser analisada e tratada com cuidado pelos gestores, uma vez que esse capital é investido nas operações e ativos com objetivo de oferecer bens e serviços para determinado mercado.

Muitas empresas têm objetivos diferentes, estes focados no crescimento, seja por vendas, seja por aumento de ativos, com aumento na participação de mercado (market share); fusões e aquisições, objetivos focados na rentabilidade e eficiência, no desenvolvimento de novos produtos e marcas, entre outros. Para o alcance desses objetivos, com base em estratégias, as empresas necessitam de recursos financeiros.

A empresa pode adquirir capital de terceiros por meio de empréstimos e financiamentos, fazer aporte de capital por meio dos sócios atuais ou, ainda, abrir o capital em bolsa de valores negociando ações preferenciais e/ou ordinárias. Abrir o capital pela primeira vez em bolsa de valores significa realizar uma oferta pública inicial de ações ou o termo em inglês Initial Public Offering (IPO).

As ofertas públicas iniciais desempenham um papel crucial na alocação de recursos nos mercados de capitais emergentes. Empresas de países emergentes têm acessado esses recursos cada vez mais, pois acreditam que podem crescer mais rápido (KIM; KITSABUNNARAT; NOFSINGER, 2004).

Apesar da importância do assunto para as empresas e demais agentes envolvidos (gestores, investidores, pesquisadores, concorrentes, entre outros), há uma escassez de estudo na literatura que aborda o tema sobre causas e efeitos do IPO, bem como o seu impacto no desempenho econômico das empresas. Na literatura internacional destacam-se os trabalhos de Jain e Kini (1994), Khurshed, Paleari e Vismara (2003), Mikkelson, Partch e Shah (1997), Wong (2012) e na literatura nacional destacam-se os trabalhos de Biral (2010), Bossolani (2009), Wardil (2009) e Zilio (2012). No geral, esses trabalhos têm analisado o desempenho de empresas em termos de vendas, rentabilidade e endividamento antes e após o IPO. Muitos dos resultados obtidos revelam declínio no desempenho das empresas, enquanto outros não verificam dife- 
renças significativas. Assim, faz-se a seguinte indagação: quais os impactos da Oferta Pública Inicial de Ações (IPO) no desempenho econômico-financeiro das empresas?

Dessa forma, neste trabalho teve-se como objetivo principal avaliar o impacto da Oferta Pública Inicial de Ações (IPO) no desempenho econômico-financeiro das empresas na B3 (Brasil, Bolsa, Balcão), antiga BM\&FBovespa, no período de 2008 a 2013.

Este trabalho se justifica pelo fato de que a realização de Oferta Pública Inicial de Ações é uma das mais importantes decisões de financiamento de uma empresa, pois não apenas afeta a estrutura de capital, mas também impacta em vários outros aspectos, como mercadológico, econômico-financeiro e cultural das organizações. Fornece informações para investidores, empresas de capital aberto e fechado, gestores de empresas e pesquisadores da área.

Nas perspectivas dos gestores de empresas e investidores no mercado de ações, a contribuição ocorre pelo fato de o trabalho investigar o desempenho das empresas antes e depois do IPO, fornecendo informações dos seus impactos sobre determinadas variáveis como vendas, retornos dos ativos e lucratividade. Essas contribuições podem auxiliar os gestores quanto à tomada de decisão de realizar IPO, e os investidores, auxiliando na tomada de decisões de investimento de empresas recém-listadas em bolsa de valores.

Por fim, o presente trabalho está estruturado em quatro seções, além desta introdução. A segunda seção compreendeu uma revisão da literatura sobre desempenho e IPO, decisões de financiamento, IPO e desempenho das empresas. Na terceira seção, tratou-se dos procedimentos metodológicos, na quarta seção foram apresentados e discutidos os resultados, e, por fim, foram realizadas as conclusões.

\section{REFERENCIAL TEÓRICO}

Nesta seção apresenta-se a revisão da literatura, as decisões de financiamento das empresas, a oferta pública inicial de ações e, por fim, o desempenho das empresas com base nos indicadores econômico-financeiros.

\subsection{REVISÃO DA LITERATURA}

Alguns estudos abordados nesta pesquisa estudaram o desempenho econômico-financeiro das empresas antes e após realização de IPO em diferentes países. Jain e Kini (1994) e Mikkelson, Partch e Shah (1997), fornecem evidencias de queda no desempenho operacional das empresas após IPO para o EUA, Pagano, Panetta e 
Zingalles (1998) para a Itália, Khurshed, Paleari e Vismara (2003) para a Inglaterra (Bolsa de Valores de Londres) e Wong (2012), para Hong Kong. No Brasil, Zilio (2012) e Wardil (2009) encontraram queda na rentabilidade auferida pelo índice $R e$ turn on Assets (ROA) das empresas após IPO enquanto Bossolani (2009), não encontrou variação na rentabilidade antes e após IPO, apesar do crescimento das vendas.

Mikkelson, Partch e Shah (1997) analisaram o controle de propriedade e o desempenho operacional das empresas que realizaram IPO. Os resultados demonstraram queda no desempenho médio operacional das empresas após IPO. Isso ocorreu, segundo Mikkelson, Partch e Shah (1997), em razão das variáveis como tamanho da empresa e idade, e não controle de propriedade. Essas conclusões vão de encontro aos resultados obtidos por Jensen e Meckling (1976), em que a redução do nível de propriedade aconteceu em decorrência do IPO e que provavelmente levará ao problema de agência, o que, consequentemente, afeta o desempenho operacional das empresas.

Jain e Kini (1994) também analisaram a mudança do desempenho operacional de empresas antes e após o IPO. Os resultados revelaram um declínio no desempenho operacional do ROA das empresas após a realização do IPO, afetado pela participação de propriedade.

Pagano, Panetta e Zingales (1998) estudaram os fatores determinantes na decisão de abrir o capital e seus efeitos econômico-financeiros no comportamento das vendas, lucratividade, rentabilidade e alavancagem. Os resultados demonstraram que apesar do crescimento das vendas, houve redução na lucratividade, rentabilidade e alavancagem após o IPO. Isso aconteceu mesmo depois de três anos de listagem.

Resultados semelhantes foram encontrados por Khurshed, Paleari e Vismara (2003), que concluíram que houve queda na rentabilidade medida pelo ROA na Bolsa de Valores de Londres. O estudo de Wong (2012) demonstrou queda no índice ROA e Return on Equity ( $R O E$ ) na Bolsa de Valores de Hong Kong, apesar do crescimento nas vendas. Para Wong (2012), o desempenho pré-IPO é exagerado, enquanto o desempenho pós-IPO pode ser subestimado, sendo essa hipótese relacionada com os resultados auferidos por Jain e Kini (1994).

Bossolani (2009) avaliou se as empresas no Brasil melhoraram seu desempenho no que se refere ao crescimento e à rentabilidade após IPO. Para isso, utilizaram dados de todas as empresas não financeiras que fizeram IPO na B3 (Brasil, Bolsa, Balcão) entre o período de janeiro de 2004 e dezembro de 2006, totalizando 36 empresas. As variáveis estudadas foram: idade das empresas, grau de alavancagem, capital levantado, estrutura acionária, retorno do patrimônio líquido $(R O E)$ e retorno dos ativos (ROA). Uma das conclusões é que, logo após o IPO, essas empresas utilizaram 
os recursos da oferta de ações para aumentar seus investimentos e acelerar o crescimento dos ativos e receitas, tornando-se menos alavancadas que no período pré-IPO. Dessa forma, uma alavancagem menor resultou em despesas financeiras menores e as empresas conseguiram manter sua rentabilidade após o IPO.

Na pesquisa realizada por Wardil (2009) foi examinado o impacto dos IPOs no tamanho, endividamento e lucratividade das empresas brasileiras. Uma das conclusões é que as empresas se tornaram menos rentáveis após o ano do IPO. A explicação para isso poderia ser o fato do capital próprio investido ter aumentado proporcionalmente mais que o retorno da empresa. Os resultados dos testes com modelos econométricos demonstraram que o IPO teve impacto positivo sobre o lucro antes dos juros, impostos e depreciação (LAJID) e a margem LAJID. O modelo mostrou um efeito negativo do IPO sobre a alavancagem financeira, ou seja, houve uma consequente diminuição da utilização do capital de terceiros.

Do exposto, fica evidente que a realização do IPO gera impactos no desempenho econômico-financeiro das empresas, sendo que uma decisão por financiamento via IPO deve ser avaliada cuidadosamente.

\subsection{DECISÕES DE FINANCIAMENTO}

Para Braga (1989), as decisões de financiamento visam montar a estrutura financeira mais adequada às operações e aos novos projetos a serem implantados na empresa. Essas decisões referem-se à composição das fontes de recursos.

Um dos índices mais importantes relacionado com a estrutura de capital é o indicador de endividamento. Segundo Groppelli e Nikbakht (2010), esse indicador mostra a proporção entre as dívidas e o patrimônio em ações emitidos pela empresa. Para Procianoy e Schnorrenberger (2004), empresas com controle acionário concentrado e aquelas com total dispersão das suas ações apresentam baixos níveis de endividamento, o que caracteriza a aversão ao risco financeiro por parte dos gestores.

Segundo Assaf Neto (2010), Damodaran (2004), Gitman (2004) e Pinheiro (2007), as fontes de financiamento externas compreendem passivo circulante e passivo não circulante. As fontes internas compreendem capital e lucros retidos. Contudo, os atuais sócios podem fazer aporte de capital. Por outro lado, também podem abrir o capital distribuindo ações preferenciais e/ou ordinárias.

Damodaran (2004) enfatiza que a forma convencional de uma empresa de capital aberto aumentar o patrimônio líquido é emitir ações ordinárias a um preço que o mercado está disposto a pagar. Já para uma empresa que começa a ser negociado 
em bolsa, o preço é estimado por um banqueiro de investimento, denominado preço de oferta. Para uma companhia mais antiga na bolsa, é baseado no preço de mercado atual.

\subsection{OFERTA PÚBLICA INICIAL DE AÇÕES (IPO)}

A empresa que acha conveniente lançar novas ações no mercado faz por meio de lançamento ou oferta pública inicial de ações oriundas do termo em inglês Initial Public Offering (IPO), em que encarrega uma instituição financeira para a coordenação e a colocação dos títulos no mercado. O IPO pode ser considerado um mecanismo por meio do qual uma empresa abre seu capital e passa a ser listada em bolsa de valores (FORTUNA, 2008; PINHEIRO, 2007).

Uma das questões ao abrir o capital é a informação. Abrir o capital significa expor os dados financeiros e operacionais da empresa ao mercado, haja vista que os investidores, para alocarem capital em uma determinada companhia, exigirão a publicação de uma série de informações para fazerem suas avaliações e decidirem investir ou não. Para tanto, é necessário um departamento de relação com investidores (OLIVEIRA, 2011).

De acordo com Hovakimian e Hutton (2010), os IPOs também facilitam aquisições de outras empresas de inúmeras maneiras. Empresas com capital recém-aberto também se beneficiam do dinheiro levantado no IPO obtendo capacidade de fazer aquisições pagando com ações.

Ao realizar uma oferta pública inicial, a empresa aumenta sua legitimidade na comunidade empresarial, melhora o acesso ao financiamento da dívida e cria um meio de saída para os principais acionistas. No entanto, de longe, a mais importante razão para ir a público é para infundir uma quantidade significativa de capital de investimento para a empresa (DEEDS et al., 1997).

Contudo, existe uma série de vantagens ao abrir o capital. Não obstante, também existem as desvantagens de realizar um IPO, conforme o Quadro 1: 
Quadro 1 - Vantagens e desvantagens do IPO

\begin{tabular}{|l|l|}
\hline \multicolumn{1}{|c|}{ Vantagens } & \multicolumn{1}{|c|}{ Desvantagens } \\
\hline $\begin{array}{l}\text { Maior acesso aos mercados financeiros e ao capi- } \\
\text { tal para os projetos. }\end{array}$ & $\begin{array}{l}\text { Estruturar departamento de acionistas e relação } \\
\text { com investidores. }\end{array}$ \\
\hline $\begin{array}{l}\text { Aumenta a liquidez e permite que os fundadores } \\
\text { colham os frutos. }\end{array}$ & Perda de controle acionário. \\
\hline $\begin{array}{l}\text { Desenvolvimento de imagem institucional junto } \\
\text { ao mercado. }\end{array}$ & Elevado custo de abertura de capital. \\
\hline $\begin{array}{l}\text { Estabelece um valor para a empresa. } \\
\text { Maior capacidade de negociação principalmente } \\
\text { em fusões. }\end{array}$ & $\begin{array}{l}\text { Passível de sofrer uma oferta pública de aquisi- } \\
\text { ção. }\end{array}$ \\
\hline $\begin{array}{l}\text { Maior flexibilidade nas decisões estratégicas da } \\
\text { empresa. }\end{array}$ & Contratação de auditoria externa. \\
\hline $\begin{array}{l}\text { Melhor solução para sucessão de empresas fami- } \\
\text { liares. }\end{array}$ & Criação de conselhos de administrativos. \\
\hline Aumenão. \\
\hline
\end{tabular}
Fonte: Damodaran (2004), Ehrhardt e Brigham (2014) e Pinheiro (2007).

É importante destacar das vantagens e desvantagens as relações com investidores. As empresas que realizaram IPO devem manter acionistas informados sobre os atuais acontecimentos. Para tanto, muitos diretores financeiros dedicam grande parte do tempo conversando com investidores e analistas (EHRHARDT; BRIGHAM, 2014).

Segundo Chemmanur e Fulghieri (1999), existem diferenças entre empresas que realizaram IPO e as que não realizaram. Para uma empresa que abriu o capital, com maior dispersão acionária, existe a necessidade de convencer um grupo muito maior de investidores de que seus projetos são um bom investimento e, por fim, o preço da ação é publicamente observável, ou seja, o preço das ações vendidas são observavéis publicamente a todos investidores externos.

Por fim, os atuais sócios ou proprietários da empresa devem estudar as condições do mercado e concretizar a conveniência de abrir o capital. Para isso, é de suma importância a contratação de auditoria externa para analisar o perfil e a situação financeira da empresa.

\subsection{DESEMPENHOS DAS EMPRESAS}

A avaliação de desempenho das empresas pode ser medida por meio de indicadores com base nas informações das demonstrações financeiras. A análise das de- 
monstrações contábeis é fundamental para conhecer a situação econômico-financeira da empresa.

Nesse sentido, Matarazzo (2010) observa que a análise das demonstrações financeiras e contábeis possibilita grande número de informações sobre as empresas. Além de auxiliar na tomada de decisões, servindo de guia para os dirigentes, proporciona informações para clientes fornecedores, concorrentes, bancos, investidores, pesquisadores e outros públicos interessados. Para Assaf Neto (2010), possibilita identificar a evolução econômico-financeira da organização, seu desempenho e eventuais tendências e projeções de possíveis resultados futuros.

Os indicadores econômico-financeiros estudados nesta pesquisa têm como base estudos realizados anteriormente de pesquisadores como Aldrighi et al. (2010), Biral (2010), Bossolani (2009), Jain e Kini (1994), Khurshed, Paleari e Vismara (2003), Mikkelson, Partch e Shah (1997), Pagano, Panetta e Zingales (1998), Wardil (2009), Wong (2012) e Zilio (2012).

Nesta pesquisa foram abordados os indicadores das variáveis tanto dependentes quanto explicativas dos modelos propostos na metodologia. Os indicadores utilizados foram: ROA, ROE, Endividamento Geral, Margem Líquida, Giro do Ativo Total e Participação do Patrimônio Líquido.

Segundo Islam, Ahmed e Hasan (2012), as das medidas de desempenho à base de contabilidade mais utilizadas pelos pesquisadores são $R O A, R O E$, crescimento das vendas, ativos totais e lucro operacional.

Os indicadores ROA e ROI de uma empresa mensuram a eficiência operacional em gerar lucros a partir dos seus ativos (DAMODARAN, 2004). É uma medida comum de desempenho gerencial (ROSS; WESTERFIELD; JAFFE, 2015). Quanto mais alto for o valor, melhor. Pode ser calculado dividindo o lucro líquido pelo ativo total (GITMAN, 2004).

De acordo com Da Silva (2013), o indicador ROE mede o retorno obtido no investimento do capital dos acionistas ordinários da empresa. Indica quanto de prêmio os acionistas da empresa estão obtendo em relação a seus investimentos no empreendimento. Em geral, quanto mais alto esse índice, melhor para os acionistas. É calculado dividindo o lucro líquido pelo patrimônio líquido. De acordo com Wardil (2009), o ROE é um dos critérios mais utilizados para medir o desempenho de empresas nas análises econômico-financeiras.

Segundo Ross, Westerfield e Jaffe (2015), o Giro do Ativo Total é um dos principais indicadores da atividade da empresa. Esse indicador mostra a eficiência com que a empresa usa seus ativos para gerar vendas. Ele é calculado dividindo-se as 
vendas pelo total de ativos. Quanto mais alto o giro do ativo de uma empresa, mais eficientemente seus ativos estão sendo usados.

O indicador de Endividamento Geral mede a proporção dos ativos totais financiados pelos credores da empresa. Quanto mais alto o valor desse indicador, maior o volume relativo de capital de outros investidores usado para gerar lucros na empresa. Pode ser calculado dividindo o passivo total pelo ativo total (GITMAN, 2004).

Credores preferem índices de endividamento baixos, pois quanto mais baixo o índice, maior a proteção contra prejuízos em caso de liquidação. Já os acionistas podem desejar uma maior alavancagem, porque isso aumenta os retornos (EHRHARDT; BRIGHAM, 2014).

Para Ross, Westerfield e Jaffe (2015), o capital próprio dos acionistas é chamado de patrimônio líquido no balanço patrimonial. O patrimônio líquido é a diferença entre o ativo total e os passivos circulante e não circulante. A Participação do Patrimônio Líquido no ativo total da empresa é medida pela divisão do valor do Patrimônio Líquido sobre o valor do ativo total.

Finalmente, a Margem Líquida é uma medida de lucratividade. Os indicadores de rentabilidade decorrem da produtividade do ativo, das margens de lucro sobre vendas e da estrutura de capital (PADOVEZE; BENEDICTO, 2010). A Margem Líquida é calculada dividindo o lucro líquido sobre a receita líquida de vendas. Essa Margem revela o lucro por unidade monetária de vendas e representa a proporção de cada unidade monetária de vendas após a dedução de todos os custos e despesas, incluindo juros, impostos e dividendos de ações preferenciais. Quanto mais alta a margem líquida melhor a lucratividade (EHRHARDT; BRIGHAM, 2014; GITMAN, 2004).

\section{METODOLOGIA}

Nesta seção apresentam-se os métodos que foram utilizados na produção deste estudo envolvendo tipo de pesquisa, objeto de estudo e amostragem, técnicas e instrumentos de coleta de dados, tratamento e variáveis utilizadas nos modelos de regressão.

A presente pesquisa é explicativa e quantitativa, pois tem o objetivo de avaliar o desempenho das empresas por meio de modelagem matemática aplicada às finanças. Constitui-se uma pesquisa bibliográfica, tratando do financiamento para empresas, bolsa de valores, abertura de capital e desempenho operacional. As fontes secundárias utilizadas advêm de livros, artigos, dissertações e de instituições referendadas como a B3 e a Comissão de Valores Mobiliários (CVM). 
Outras fontes de dados secundários utilizadas foram demonstrações financeiras, por meio do balanço patrimonial e de demonstração do resultado do exercício, de empresas que realizaram IPO no período de 2008 a 2013.

No presente trabalho o objeto de estudo contemplou uma amostra de empresas que realizaram IPO na B3 no período de 2008 a 2013, no caso uma população amostral de 45 empresas. Para tanto, foi necessário identificar as empresas brasileiras que realizaram IPO no período de 2008 a 2013, bem como levantar seus relatórios financeiros. Contudo, da amostra inicial sobraram 28 empresas em razão dos seguintes aspectos: fechamento de capital, empresas em recuperação judicial, instituições bancárias, entre outros.

A população amostral tem como ponto de partida a crise internacional dos subprimes de 2008, considerando empresas que realizaram IPO dessa data em diante até 31 de dezembro de 2013. Foram necessárias informações antes e depois do IPO para todas as empresas. Empresas que realizaram IPO no ano 2014 em diante não foram incluídas na amostra por causa da pouca disponibilidade de dados pós-IPO. A seguir, o Quadro 2 apresenta a população amostral final:

Quadro 2 - População amostral final

(continua)

\begin{tabular}{|c|c|c|c|}
\hline Empresas & $\begin{array}{l}\text { Ano do } \\
\text { (IPO) }\end{array}$ & $\begin{array}{l}\text { Período de dados } \\
\text { analisados }\end{array}$ & Setor na bolsa em que a empresa atua \\
\hline NUTRIPLANT & 2008 & $2005-2015$ & Fertilizantes e defensivos \\
\hline HYPERMARCAS & 2008 & $2005-2015$ & Produtos diversos \\
\hline LE LIS BLANC & 2008 & $2005-2015$ & Tecidos, vestuário e calçados \\
\hline CETIP & 2009 & 2006-2015 & Serviços financeiros diversos \\
\hline DIRECIONAL & 2009 & 2006-2015 & Construção civil \\
\hline FLEURY & 2009 & 2006-2015 & Serv. méd. hospit., análises e diagnósticos \\
\hline ALIANSCE & 2010 & $2007-2015$ & Exploração de imóveis \\
\hline BR PROPERT & 2010 & $2007-2015$ & Exploração de imóveis \\
\hline ECORODOVIAS & 2010 & $2007-2015$ & Exploração de rodovias \\
\hline MILLS & 2010 & 2007-2015 & Serviços diversos \\
\hline JULIO SIMOES & 2010 & 2007-2015 & Transporte rodoviário \\
\hline RENOVA & 2010 & 2007-2015 & Energia elétrica \\
\hline RAIA & 2010 & 2007-2015 & Medicamentos \\
\hline AREZZO CO & 2011 & 2008-2015 & Tecidos, vestuário e calçados \\
\hline SIERRABRASIL & 2011 & $2008-2015$ & Exploração de imóveis \\
\hline
\end{tabular}




\begin{tabular}{|c|c|c|c|}
\hline Empresas & $\begin{array}{l}\text { Ano do } \\
\text { (IPO) }\end{array}$ & $\begin{array}{l}\text { Período de dados } \\
\text { analisados }\end{array}$ & Setor na bolsa em que a empresa atua \\
\hline TIME FOR FUN & 2011 & 2008-2015 & Produção de eventos e shows \\
\hline MAGAZ LUIZA & 2011 & 2008-2015 & Eletrodomésticos \\
\hline QUALICORP & 2011 & 2008-2015 & $\begin{array}{l}\text { Serv. méd. hospit., análises e diagnós- } \\
\text { ticos }\end{array}$ \\
\hline TECHNOS & 2011 & 2008-2015 & Acessórios \\
\hline LOCAMERICA & 2012 & 2009-2015 & Aluguel de carros \\
\hline UNICASA & 2012 & 2009-2015 & Móveis \\
\hline LINX & 2013 & 2010-2015 & Programas e serviços \\
\hline SENIOR SOL & 2013 & 2010-2015 & Programas e serviços \\
\hline BIOSEV & 2013 & 2010-2015 & Açúcar e álcool \\
\hline ALUPAR & 2013 & 2010-2015 & Energia elétrica \\
\hline ANIMA & 2013 & 2010-2015 & Serviços educacionais \\
\hline SER EDUCA & 2013 & 2010-2015 & Serviços educacionais \\
\hline CVC BRASIL & 2013 & $2010-2015$ & Viagens e turismo \\
\hline
\end{tabular}

Fonte: os autores.

As informações utilizadas abrangeram até três anos antes do IPO e no mínimo dois anos depois, pois empresas que fizeram IPO em 2013 tiveram informações disponíveis até 2015. Os dados coletados nas demonstrações financeiras foram tratados no Excel ${ }^{\circ}$ e no programa estatístico Gretl.

A crise internacional dos subprimes afetou a economia e o mercado de capitais no Brasil. A quantidade de IPOs reduziu em relação aos anos anteriores. A crise também afetou as vendas e os lucros das empresas. A amostra serviu de base para procedimentos de estatística descritiva e multivariada, sendo utilizada a análise de regressão linear múltipla.

Para tratar os dados, foi utilizado o procedimento estatístico com teste de hipóteses paramétrico. Nesse procedimento foi utilizada uma técnica de estatística multivariada, a análise de regressão linear múltipla com o emprego do método dos mínimos quadrados generalizados.

A análise de regressão é a técnica de dependência mais amplamente usada e versátil. Sua utilização varia desde os problemas mais gerais até os mais específicos. A análise de regressão é o fundamento para os modelos de previsão em negócios variando desde modelos econométricos que preveem a economia nacional até modelos de desempenho de uma empresa (HAIR JUNIOR et al., 2009). 
Conforme Fávero et al. (2009) e Gujarati e Porter (2011), o objetivo da análise de regressão é estudar a relação entre duas ou mais variáveis explicativas que apresentam forma linear e uma variável dependente métrica. Assim, um modelo de regressão linear, de modo geral, pode ser escrito da seguinte forma:

$$
\mathrm{Y}=\alpha+\beta_{1} \mathrm{X}_{1}+\beta_{2} \mathrm{X}_{2+\ldots \ldots}+\beta_{\mathrm{n}} \mathrm{X}_{\mathrm{n}+} u
$$

Em que:

$\mathrm{Y}$ = fenômeno do estudo (variável dependente métrica);

$\alpha=$ representa o intercepto (constante);

$\beta_{\mathrm{k}}=$ são os coeficientes de cada variável (coeficientes angulares);

$u=$ distúrbio ou termo de erro.

O distúrbio também conhecido como resíduo representa possíveis variáveis $\mathrm{X}$ que não foram inseridas no modelo e que seriam variáveis explicativas da variável Y (FÁVERO et al., 2009).

Nesta pesquisa foi utilizada a técnica de dados em painel. Os modelos envolvem dados provenientes de várias cross sections ao longo do tempo. Fávero et al. (2009) e Gujarati e Porter (2011) afirmaram que, combinando séries temporais com observações de corte transversal, os dados em painel oferecem redução de problemas de multicolinearidade de variáveis explicativas, geram dados mais informativos, maior variabilidade, mais eficiência e maior grau de liberdade.

Contudo, para dados em painel, foram utilizadas duas abordagens: modelo de efeitos fixos e modelo de efeitos aleatórios. Para Fávero et al. (2009), os modelos fixos consideram as alterações nas cross sections ao longo do tempo, podem ser escritos da seguinte maneira:

$$
\mathrm{Y}_{\mathrm{it}}=\alpha \cdot D_{\mathrm{i}}+\beta_{1} \mathrm{X}_{\mathrm{it}}+u_{\mathrm{it}}
$$

Em que o intercepto de cada observação corresponderá à sua Dummy $D_{\mathrm{i}}$. O subscrito ${ }_{i}$ no termo intercepto sugere que os interceptos das observações (empresas) podem ser diferentes em razão das características peculiares de cada observação (FÁVERO et al., 2009).

Os modelos de efeitos aleatórios ou modelos de componentes de erros são compostos por dois ou mais erros. Se as variáveis representam falta de conhecimento 
sobre o modelo, essa informação pode ser expressa pelo termo de erro (GUJARATI; PORTER, 2011).

De acordo com Fávero et al. (2009), o modelo de efeitos aleatórios pode ser escrito da seguinte forma:

$$
\mathrm{Y}_{\mathrm{it}}=\alpha_{i}+\beta_{1} \mathrm{X}_{\mathrm{it}}+w_{i t}
$$

Segundo Gujarati e Porter (2011), o termo de erro composto $w_{i t}$ consiste em dois componentes: componente de corte transversal ou específico das empresas e elemento de erro combinando a série temporal e o corte transversal. Este às vezes é chamado de termo idiossincrático, pois varia com a empresa e o tempo. A diferença entre o efeito fixo e o aleatório é a forma como o componente de erro individual é tratado.

As análises dos resultados dos modelos de regressão são feitas em inferência estatística com base nas observações da amostra levando em consideração o nível de significância.

Segundo Hair Junior et al. (2009), o nível de significância ou erro de tipo I representa a probabilidade que o pesquisador deseja aceitar de que o coeficiente estimado seja classificado como diferente de zero quando realmente não é. O nível de significância amplamente usado é de 0,05, apesar de pesquisadores utilizarem níveis que variam de 0,01 a 0,10 .

\subsection{VARIÁVEIS E MODELOS}

As variáveis utilizadas na pesquisa estão relacionadas a seguir. Essas variáveis são baseadas em estudos antecedentes como os de Bossolani (2009), Khurshed, Paleari e Vismara (2003), Pagano, Panetta e Zingales (1998), Wardil (2009) e Zilio (2012). Além disso, foi utilizado o método Stepwise para avaliar a significância estatística dos parâmetros de cada variável explicativa, considerando para os modelos finais apenas variáveis que não apresentaram problemas de multicolinearidade:
a) Vendas - Receita Líquida de Vendas it; $_{\text {; }}$
b) Tamanho - Logaritmo do Ativo Total ${ }_{\mathrm{it}}$;
c) Giro do Ativo ;
d) Margem Líquida - $\mathrm{ML}_{\mathrm{it}}$;
e) Retorno dos Ativos $-\mathrm{ROA}_{\mathrm{it}}$;
f) Retorno do Patrimônio Líquido $-R O E_{\mathrm{it}}$; 
g) IPO - Variável Dummy;

h) Endividamento Geral $_{\mathrm{it}}$.

Para Aldrighi et al. (2010), a variável "vendas" é uma proxy do tamanho da empresa. Como existe grande variabilidade entre as receitas das empresas na amostra, foi utilizado logaritmo natural da receita. Portanto, a variável de crescimento das empresas é medida pelo Logaritmo da Receita Líquida de Vendas e o tamanho foi medido pelo Logaritmo do Ativo Total (AT) de cada empresa $i$ no período $t$.

A variável “IPO” foi incluída como variável Dummy para captar os impactos no desempenho antes e depois do IPO. Foram atribuídos valores zero para as empresas antes do IPO e um para empresas que realizaram IPO.

Os modelos de regressão, nesta pesquisa, compreendem modelo de crescimento, dois modelos de retorno ( $R O A$ e $R O E$ ) e um modelo de lucratividade. Para cada modelo foi elaborada uma hipótese com base em estudos antecedentes dos autores já mencionados.

Hipótese 1: Após IPO, as empresas têm mais acesso a recursos financeiros e expandem suas vendas e mercados.

$$
\text { RecLiqVendas }=a_{0}+\text { B1EndGeral }_{\mathrm{it}}+\text { B2GiroAT }_{\mathrm{it}}+\text { B3DummyIPO }+\mathrm{u}_{i t}
$$

As receitas representam as vendas realizadas. Para analisar o impacto da oferta inicial foi utilizada a variável Dummy IPO. As variáveis de controle utilizadas nesse modelo foram o endividamento geral (alavancagem) e o giro do ativo, este último indicando a eficiência com que a empresa usa seus ativos para gerar vendas.

Hipótese 2: Com aumento das vendas, a rentabilidade medida pelo $R O A$ aumenta depois da realização do IPO.

$$
\begin{gathered}
R O A_{i t}=\mathrm{A}_{0}+\text { B1Log.AtivoTotal } \\
\text { it }
\end{gathered}
$$

As variáveis de controle de crescimento (receita líquida de vendas), tamanho (ativo total) e giro do ativo foram incluídas. Além dessas variáveis foram incluídas o $R O A$ que depende da capacidade de seus ativos operacionais, o efeito do endividamento geral e a variável IPO (Dummy). 
Hipótese 3: Com a entrada de novos recursos por meio do IPO e o aumento das vendas, as empresas melhoram sua rentabilidade do patrimônio líquido.

$$
\begin{gathered}
R O E=\mathrm{A}_{0}+\text { B1RecLiqVendas }_{\mathrm{it}}+\text { B2EndGeral }_{\mathrm{it}}+ \\
\text { B3GiROAT }_{\mathrm{it}}+\text { B4MargemLiq }_{\mathrm{it}}+\text { B5DummyIPO }+\mathrm{u}_{i t}
\end{gathered}
$$

Hipótese 4: Com a entrada de novos recursos financeiros pela realização do IPO e o aumento das receitas líquidas de vendas, as empresas aumentam a lucratividade das vendas líquidas medida pela variável margem líquida.

$$
\begin{gathered}
\text { MargemLiqit }=A_{0}+\text { B1Participação } P L_{i t}+\text { B2Tamanho }(\text { Log.AT })_{i t}+ \\
\text { B3DummyIPO }+\mathrm{u}_{i t}
\end{gathered}
$$

Com a hipótese de aumento das vendas, supõe-se que a margem líquida aumente também. A variável IPO foi inserida como variável Dummy e as variáveis de tamanho e de participação do patrimônio líquido como variáveis de controle.

\section{RESULTADOS E DISCUSSÃO}

Os resultados obtidos compreendem a estatística descritiva das variáveis e os resultados dos modelos econométricos de crescimento, rentabilidade dos ativos e patrimônio líquido e lucratividade das vendas líquidas.

A Tabela 1 tem como objetivo mostrar os resultados da estatística descritiva das variáveis dependentes estudadas na pesquisa. As variáveis analisadas compreendem o período de 2005 a 2015, variando de empresa para empresa com base no ano do IPO, gerando 230 observações para cada variável nos modelos de regressão.

As informações compreendem média, desvio padrão, valor mínimo e máximo das variáveis em três períodos distintos (pré-IPO, ano do IPO e pós-IPO).

As informações utilizadas abrangeram até três anos antes do IPO para todas as empresas. No período pós-IPO, no caso das empresas que abriram capital em 2013, foram analisados até dois anos pós-IPO.

As observações individuais de cada empresa foram separadas em três períodos distintos. Portanto, para melhor entendimento, como exemplo, no período antes do IPO que compreende três anos anteriores ao IPO para todas as empresas, foi calculada a média desse período para cada empresa e posteriormente calculada a média geral de todas as empresas contabilizando 28 observações médias representadas pela 
letra "N" na Tabela 1. Em todos os períodos foram realizados esses cálculos abrangendo a média, o desvio padrão, o valor mínimo e o máximo. A variável Log. Rec. Líquida está em formato de logaritmo e as demais variáveis em percentuais.

Tabela 1 - Estatísticas descritivas das variáveis dependentes em painel

\begin{tabular}{lcrrrr}
\hline \multicolumn{1}{c}{ Variável } & N & \multicolumn{1}{c}{ Média } & Desvio padrão & \multicolumn{1}{c}{ Mínimo } & \multicolumn{1}{c}{ Máximo } \\
\hline Rec. Líquida Pré-IPO & 28 & 5,76 & 5,92 & 4,21 & 6,55 \\
Rec. Líquida IPO & 28 & 5,97 & 6,13 & 4,56 & 6,80 \\
Rec. Líquida Pós-IPO & 28 & 6,20 & 6,30 & 4,60 & 6,93 \\
ROA Pré-IPO & 28 & 7,14 & 9,51 & $-11,56$ & 27,49 \\
ROA IPO & 28 & 7,11 & 7,59 & $-6,36$ & 19,32 \\
ROA Pós-IPO & 28 & 4,27 & 6,19 & $-10,13$ & 14,77 \\
ROE Pré-IPO & 28 & 39,60 & 134,59 & 117,15 & 528,57 \\
ROE IPO & 28 & 12,01 & 15,03 & $-25,14$ & 35,31 \\
ROE Pós-IPO & 28 & 0,55 & 48,69 & $-169,86$ & 29,13 \\
ML Pré-IPO & 28 & 10,83 & 30,22 & $-53,41$ & 97,48 \\
ML IPO & 28 & 32,29 & 100,05 & $-15,59$ & 397,80 \\
ML Pós-IPO & 28 & 14,40 & 27,59 & $-22,71$ & 100,52 \\
Fonte: os autores. & & & & &
\end{tabular}

A Tabela 1 demonstra a média, os valores mínimos, os máximos e o desvio padrão das observações individuais de cada empresa separadas em três períodos: pré-IPO, ano do IPO e pós-IPO. A variável receita líquida de vendas tem os valores em formato de logaritmo na tabela. A média é crescente do período pré-IPO para o período pós-IPO no valor logaritmizado de 6,20. Esse número representa, em média, o valor de mais de um bilhão e meio de reais em receitas líquidas de vendas.

O valor mínimo encontrado da receita líquida de vendas foi de 4,21, o que representa aproximadamente 16 milhões de reais. O valor máximo foi de 6,93 no período pós-IPO. Esse valor representa quase 9 bilhões de reais em vendas.

Com base na Tabela 1, é possível notar que a média da variável $R O A$ reduz no período pós-IPO para 4,27\%. Os valores mínimo e máximo foram detectados no período pré-IPO no valor de -11,56\% e 27,49\%, respectivamente. Esse valor máximo do $R O A$ pré-IPO cai para 14,77\% pós-IPO. Contudo, nessa análise, deve-se considerar que há grande variabilidade do tamanho das empresas variando de setor em setor.

A variável $R O E$ também teve queda média no período pós-IPO. O valor médio da variável $R O E$ no período pós-IPO foi de $0,55 \%$. No período pré-IPO esse valor era de $39,60 \%$. O maior valor mínimo se encontra no período pós-IPO e o maior valor 
máximo (528,57\%) no período pré-IPO. O maior desvio padrão encontrado foi no período pré-IPO no valor de 134,59\%.

As médias da variável margem líquida tiveram valores de 10,83\% e 14,40\% pós-IPO. O maior desvio padrão encontrado para a margem líquida foi no ano do IPO no valor de $100,05 \%$ com valores variando de $-15,59 \%$ e $397,80 \%$.

\subsection{RESULTADOS DOS MODELOS DE CRESCIMENTO}

Vale ressaltar que os dados se encontram em painel desbalanceado, uma vez que não há quantidade igual de períodos para cada uma das empresas estudadas. Somado a essa informação, também existe o fato de as datas de realização dos IPOs variarem de 2008 a 2013.

A Tabela 2 mostra os resultados do modelo de regressão da receita líquida de vendas como variável dependente. Essa variável representa o modelo de crescimento. Com base no teste de Hausman, foi escolhido o modelo de efeitos aleatórios. A significância do teste de Hausman foi de 0,3607 aceitando a hipótese nula do teste. Todos os modelos apresentados possuem 230 observações, cada variável em um total de 28 empresas.

Tabela 2 - Resultado do modelo de crescimento

\begin{tabular}{lrrrr}
\hline \multicolumn{1}{c}{ Receita Líq. de Vendas } & \multicolumn{1}{c}{ Coeficiente } & Desvio padrão & \multicolumn{1}{c}{$\mathbf{z}$} & \multicolumn{2}{c}{ Z Valor } \\
\hline End. Geral & 0,1682 & 0,3448 & 0,49 & 0,626 \\
Giro AT & 0,0737 & 0,1456 & 0,51 & 0,612 \\
IPO & 0,5383 & 0,0904 & 5,95 & $0,000^{*}$ \\
Const. & 5,2158 & 0,1640 & 31,80 & $0,000^{*}$ \\
\hline Fonte: os autores. & & &
\end{tabular}

Nota: Os valores significantes a 1\%, 5\% e 10\% estão indicados por *, ** e ***, respectivamente.

De acordo com a Tabela 2 a variável Dummy IPO nesse modelo é significante a $1 \%$. As outras variáveis de controle não restaram ser estatisticamente significativas. Nesse modelo, sem a variável de Tamanho, o IPO afetou as vendas positivamente, ou seja, as empresas que fizeram IPO aumentaram em média 53,83\% das vendas. Esses resultados apontam na direção em que o IPO gerou um impacto no Ativo Total que, consequentemente, afetou as vendas de maneira positiva.

Esses resultados são similares com os resultados dos estudos de Aldrighi et al. (2010), Bossolani (2009), Wardil (2009) e Wong (2012). O processo de IPO afetou as vendas que aumentaram mais que proporcionalmente no período pré-IPO. 
Resultados obtidos por Wardil (2009) mostraram que as empresas se encontravam excessivamente alavancadas antes do IPO, e com a oferta pública inicial de ações, tornaram-se menos endividadas. Logo após o IPO as empresas utilizaram os recursos advindos para aumentar seus investimentos e acelerar as receitas e ativos.

Além disso, a injeção de capital com a realização do IPO aumentou os ativos das empresas conforme demonstrado no Gráfico 1. As informações contidas no Gráfico em tela mostram a evolução média dos ativos totais das empresas nos períodos pré-IPO, ano do IPO e pós-IPO com a evolução das receitas líquidas de vendas.

Com base no Gráfico 1 é possível detectar a influência do IPO tanto nas receitas líquidas de vendas quanto nos ativos totais. Ambas as linhas, a partir do ano do $I P O$, apresentam uma forte inclinação para cima. É possível observar que os ativos totais triplicaram do período pré-IPO para o período pós-IPO com um valor médio de R\$ 3.664,3 bilhões.

Gráfico 1 - Evolução Média da Receita Líquida de Vendas e Ativos Totais

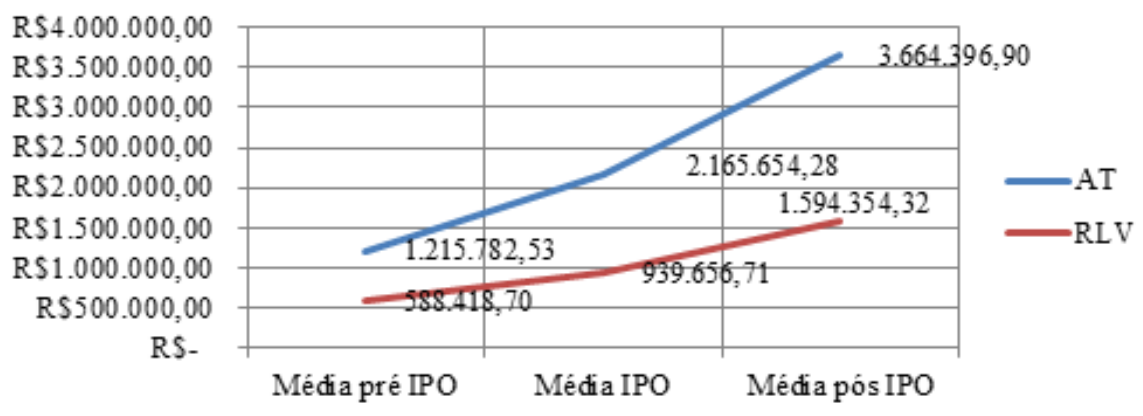

Fonte: os autores.

Nota: Valores em milhares de reais (R\$).

\subsection{RESULTADOS DOS MODELOS DE RENTABILIDADE}

Conforme a Tabela 1, após o IPO o $R O A$ declina de $7,11 \%$ para $4,27 \%$. A Tabela 3 mostra os resultados do modelo de regressão dos $R O A$ como variável dependente. Com base no teste de Hausman foi escolhido o modelo de efeitos fixos com significância no valor de 0,0119. A hipótese nula foi rejeitada, a qual diz que o modelo de correção dos erros não é adequado ou que os efeitos individuais não são aleatórios. 
Tabela 3 - Resultados do Modelo ROA

\begin{tabular}{|c|c|c|c|c|}
\hline ROA & Coeficiente & Desvio padrão & $\mathbf{t}$ & T Valor \\
\hline End. Geral & $-0,2061$ & 0,0551 & $-3,74$ & $0,001^{*}$ \\
\hline Tamanho & 0,0417 & 0,0200 & 2,08 & $0,048 * *$ \\
\hline ML & 0,0698 & 0,0213 & 3,27 & $0,003 *$ \\
\hline Giro AT & 0,1176 & 0,0160 & 7,32 & $0,000 *$ \\
\hline IPO & $-0,0438$ & 0,0149 & $-2,94$ & $0,007 *$ \\
\hline Const. & $-0,1459$ & 0,1031 & $-1,41$ & 0,169 \\
\hline
\end{tabular}

De acordo com a Tabela 3 todas as variáveis de controle e a variável Dummy $I P O$ são significativas. Isso significa que as variáveis independentes afetaram a variável dependente ROA. Contudo, algumas variáveis afetaram o ROA de maneira positiva, enquanto outras, de modo negativo.

A variável Margem Líquida (ML) teve um coeficiente positivo e teste $\mathrm{t}$ value de 3,27 a um nível de significância a 1\%, resultando em efeitos positivos na rentabilidade média dos ativos em 6,98\%. Assim, como a Margem Líquida, o Giro do Ativo Total teve coeficiente positivo, teste t value de 7,32\% a um nível de significância de até $1 \%$ com efeitos positivos na rentabilidade média dos ativos em 11,76\%. A variável de Tamanho, representada pelo Log. do Ativo Total, também foi influente de forma positiva no ROA a um nível de significância de 5\%.

Por outro lado, a variável Dummy IPO afetou negativamente o ROA. A variável Dummy IPO teve coeficiente negativo e teste t value de -2,94 a um nível de significância de até 1\% (t value), resultando em efeitos negativos na rentabilidade média do $R O A$ em $-4,38 \%$.

Para autores como Khurshed, Paleari e Vismara (2003) e Pagano, Panetta e Zingales (1998), esse resultado deve-se ao aumento mais do que proporcional dos ativos em relação à receita líquida de vendas. Resultado esse diferente dos resultados de Bossolani (2009), que não encontrou diferenças no $R O A$ nos períodos pré e pós-IPO, concluindo que a rentabilidade dos ativos no período foi mantida. Alguns pesquisadores como Khurshed, Paleari e Vismara (2003), Pagano, Panetta e Zingales (1998) e Wong (2012) encontraram queda do ROA após IPO.

A Tabela 4 mostra os resultados da regressão do ROE como variável dependente. Com base no teste de Hausman foi escolhido o modelo de efeitos aleatórios. A significância do teste foi no valor de 0,6446. 
Tabela 4 - Resultados do Modelo ROE

\begin{tabular}{|c|c|c|c|c|}
\hline ROE & Coeficiente & Desvio padrão & $\mathbf{z}$ & Z Valor \\
\hline ML & 0,4757 & 0,2631 & 1,81 & $0,071^{* * *}$ \\
\hline End. Geral & 0,1861 & 0,4862 & 0,38 & 0,702 \\
\hline Vendas & 0,3531 & 0,1661 & 2,13 & $0,034 * *$ \\
\hline Giro AT & 0,2092 & 0,1032 & 2,03 & $0,043 * *$ \\
\hline IPO & $-0,5241$ & 0,2639 & $-1,99$ & $0,047 * *$ \\
\hline Const. & $-1,8428$ & 0,8663 & $-2,13$ & $0,033 * *$ \\
\hline
\end{tabular}

Fonte: os autores.

Nota: Os valores significantes a $1 \%, 5 \%$ e $10 \%$ estão indicados por *, ** $\mathrm{e}^{* * *}$, respectivamente.

Conforme a Tabela 4, as variáveis ML, Rec. Líquida e Giro. AT. foram significantes e afetaram de forma positiva o ROE. Por outro lado, o IPO afetou de forma negativa o ROE em -52,41\%. O coeficiente da variável denominada End. Geral não foi estatisticamente significativo, dessa forma, não podendo fazer qualquer inferência no que se refere ao $R O E$.

O coeficiente da variável ML teve teste z value de 1,81 a um nível de significância de até $10 \%$, o qual resultou em efeitos positivos na rentabilidade média do $R O E$ em 47,57\%. Já o Giro do Ativo obteve coeficiente positivo e teste z value de 2,03 a um nível de significância de 5\%, resultando em efeitos positivos na rentabilidade média do $R O E$ em 20,92\%. Em relação ao impacto das vendas no $R O E$, a cada $1 \%$ no aumento das vendas houve aumento de 35,31\% na rentabilidade média do ROE.

Porém, a variável Dummy IPO obteve coeficiente negativo e teste z value de -1,99 a um nível de significância de até $5 \%$ resultando em efeitos negativos na rentabilidade média do $R O E$ em 52,41\%, ou seja, em média a realização do IPO afetou negativamente de forma acentuada a variável dependente $R O E$. Com base na literatura estudada, existem algumas explicações para a queda das rentabilidades.

Esses resultados são similares aos achados de Cai e Wei (1997), Khurshed, Paleari e Vismara (2003), Pagano, Panetta e Zingales (1998) e Wong (2012), que encontraram queda no desempenho do ROE.

De acordo com Pagano, Panetta e Zingales (1998), a queda da rentabilidade está realmente associada com a realização do IPO e não apenas da regressão da média ou do efeito de alguma outra variável na rentabilidade. Segundo esses autores, outra explicação que tem relacionamento com a queda da rentabilidade são as mudanças contábeis trazidas pela decisão de abrir o capital. Na preparação de suas contas para abrir o capital, as empresas, ao fazerem oferta pública inicial de ações, tentam for- 
necer uma imagem justa do valor de seus ativos, enquanto as empresas privadas de capital fechado estão mais preocupadas em ocultar seu valor das autoridades fiscais.

Para Cai e Wei (1997) e Degeorge e Zeckhauser (1993), essa queda na rentabilidade não é uma surpresa e é um forte indício no qual os empresários aproveitam a janela de oportunidade. Segundo Mikkelson, Partch e Shah (1997), as empresas, principalmente as maiores, aproveitaram a janela de oportunidade, na qual os gestores aproveitaram períodos de alto desempenho para emitir ações no mercado para investidores com altas expectativas.

Outra explicação para a queda da rentabilidade está no window dressing. De acordo com Khurshed, Paleari e Vismara (2003), o window dressing significa gerenciamento de resultados antes do IPO. Esse gerenciamento de resultados pode acentuar ainda mais a queda da rentabilidade após a emissão de ações.

\subsection{RESULTADOS DO MODELO DE LUCRATIVIDADE}

Conforme a Tabela 1, após o IPO a ML média declina de forma acentuada de $32,29 \%$ para $14,40 \%$. No entanto, a média pós IPO é maior do que o período pré IPO com media de 14,40\% e 10,83\% respectivamente. Esses resultados confirmam que as Receitas Líquidas de Vendas e a Margem Líquida foram maiores pós-IPO e menores pré-IPO.

A Tabela 5 mostra os resultados do modelo de regressão da Margem Líquida como variável dependente. Com base no teste de Hausman foi escolhido o modelo de aleatórios. O valor da significância do teste foi de 0,3733. A hipótese nula foi aceita, na qual o modelo de correção dos erros é adequado.

As variáveis de participação do patrimônio líquido e tamanho foram significantes e afetaram positivamente a variável Margem líquida. A variável IPO não teve significância no modelo, ou seja, o IPO não gerou impactos na variável margem líquida.

Tabela 5 - Resultados do Modelo Margem Líquida (ML)

\begin{tabular}{|c|c|c|c|c|}
\hline ML & Coeficiente & Desvio padrão & $\mathbf{z}$ & Z Valor \\
\hline Participação PL & 0,4728 & 0,1326 & 3,57 & $0,000 *$ \\
\hline Tamanho & 0,1333 & 0,0526 & 2,53 & $0,011^{* *}$ \\
\hline IPO & $-0,0591$ & 0,0512 & $-1,15$ & 0,249 \\
\hline Const. & $-0,8308$ & 0,3270 & $-2,54$ & $0,011^{* *}$ \\
\hline
\end{tabular}

Nota: Os valores significantes a $1 \%, 5 \%$ e $10 \%$ estão indicados por *, ** e ***, respectivamente. 
A variável Participação do PL teve coeficiente positivo e teste z value no valor de 3,57 a um nível de significância de 1\%, resultando em efeitos positivos na lucratividade média da Margem Líquida em 47,28\%. O tamanho também afetou a margem líquida. A cada $1 \%$ de aumento no Ativo Total gerou um aumento de 0,13\% na Margem Líquida.

Como resultados, o modelo aceitou a primeira hipótese. Já as segunda e terceira hipóteses foram rejeitadas, pois nos modelos econométricos o IPO afetou negativamente a rentabilidade dos ativos e do patrimônio líquido. Vale destacar que houve uma queda média do $R O E$ de $39,60 \%$ pré-IPO para 0,55\% no período pós-IPO.

Também é importante frisar que na Hipótese 4 (H4) a variável Dummy IPO não teve impactos na Margem Líquida. Os resultados da Margem Líquida, apesar de serem maiores no período pós-IPO do que no período pré-IPO, apresentaram tendência de queda futura. Portanto, sugere-se para futuras pesquisas uma análise com períodos maiores pós-IPO.

\section{CONCLUSÃO}

O objetivo do estudo foi avaliar o impacto do IPO no desempenho econômico e financeiro das empresas na BM\&FBovespa, no período de 2008 a 2013 . O desempenho foi analisado em termos de crescimento das receitas líquidas de vendas, rentabilidade dos ativos e do patrimônio líquido e lucratividade das vendas líquidas compreendendo os períodos pré-IPO, ano do IPO e pós-IPO das empresas. Teve como base de dados uma amostra contendo empresas que realizaram oferta pública inicial de ações no período de 2008 a 2013.

Para analisar o desempenho do crescimento, rentabilidade e lucratividade, foram estimados modelos de regressão linear múltipla com as seguintes variáveis dependentes: Crescimento da Receita Líquida de Vendas, ROA, ROE e Margem Líquida.

Os primeiros resultados mostraram que as empresas analisadas estavam com as receitas líquidas originadas das vendas em crescimento nos três anos antes de realizarem IPO.

No período pós-IPO foi constatado, em média, um aumento abrupto das receitas líquidas de vendas. Essa expansão remete à primeira hipótese de que o mercado de capitais é benéfico para as empresas, fazendo com que as receitas e os ativos se desenvolvam, consequentemente, expandindo a disponibilidade de produtos e serviços para os consumidores/clientes dos mercados em que essas empresas atuam. 
Os resultados compreendendo a rentabilidade das empresas por meio do $R O A$ e do $R O E$ foram estatisticamente significativos, ou seja, o IPO afetou a rentabilidade só que esse impacto foi negativo. A hipótese de que o IPO aumenta a rentabilidade foi rejeitada. De acordo com os resultados do modelo de regressão, a rentabilidade média reduziu no período pós-IPO. Tanto o ROA quanto o $R O E$ resultaram em piora no desempenho pós-IPO.

Os resultados envolvendo lucratividade por meio da variável Margem Líquida apontam em média para resultados elevados no ano do IPO com base nas estatísticas descritivas, apesar da variável Dummy IPO não se apresentar estatisticamente significativa no modelo de regressão.

Contudo, de maneira geral, o IPO teve impacto sobre as variáveis estudadas nesta pesquisa, ou seja, a oferta pública inicial de ações capitalizou as empresas aumentando investimentos, com consequente aumento das receitas e ativos, apesar da redução da rentabilidade medida pelo $R O A$ e pelo $R O E$. Já o modelo de regressão da lucratividade não apresentou efeito do IPO sobre a margem líquida.

Por fim, para futuras pesquisas, sugere-se análise compreendendo empresas com tamanhos padronizados, maiores períodos, além de períodos econômicos menos turbulentos, com maiores e novas amostras analisando e comparando possivelmente empresas de outros países emergentes ou fazendo comparações setoriais.

\section{REFERENNCIAS}

ALDRIGHI, D. M. et al. As ofertas públicas iniciais na Bovespa no período recente: características das empresas, estrutura de propriedade e de controle, e desempenho. In: ENCONTRO NACIONAL DE ECONOMIA, 38., 2010, Salvador. Anais... Salvador: ANPEC, 2010. 1 CD-ROM. Disponível em: <https://scholar.google. com.br/scholar?hl=ptBR\&as_=0\%2C5\&q=as+ofertas+p\%C3\%BAblicas+iniciais+na+bovespa+no+per\%C3\%ADodo+\&btnG=> . Acesso em: 15 mar. 2017.

ASSAF NETO, A. Finanças Corporativa e Valor. 5. ed. São Paulo: Atlas, 2010.

BIRAL, R. A. F. A abertura de capital afeta o desempenho operacional das empresas? Uma evidência da onda de IPOS 2004-2008. 2010. 50 p. Dissertação (Mestrado Profissional)-Fundação Getúlio Vargas, 2010.

BM\&FBOVESPA. 2017. Disponível em: <http://www.bmfbovespa.com.br/pt_br/ institucional/sobre-a-bm-fbovespa/quem-somos>. Acesso em: 21 jan. 2017. 
BOSSOLANI, T. IPO e o desempenho das empresas. 2009. 56 p. Dissertação (Mestrado em Finanças e Economia Empresarial)-Fundação Getúlio Vargas, São Paulo, 2009.

BRAGA, R. Fundamentos e técnicas de administração financeira. São Paulo: Atlas, 1989.

CAI, J.; WEI, K. C. J. The investment and operating performance of Japanese initial public offerings. Pacific-Basin Finance Journal, Oxford, v. 5, i. 4, p. 389-417, 1997. Disponível em: <https://www.scopus.com/record/display. uri?eid=2-s2.0-0031231866\&origin=inward $>$. Acesso em: 02 fev. 2017.

CHEMMANUR, T. J.; FULGHIERI, P. A theory of the going-public decision. Review of Financial Studies, New York, v. 12, i. 2, p. 249-279, 1999.

DAMODARAN, A. Finanças corporativas: teoria e prática. 2. ed. Porto Alegre: Bookman, 2004.

DA SILVA, J. P. Análise financeira das empresas. 12. ed. São Paulo: Atlas, 2013.

DEEDS, D. L et al. The impact of firmspecific capabilities on the amount of capital raised in an initial public offering: evidence from the biotechnology industry. Journal of Business Venturing, New York, v. 12, i. 1, p. 31-46, jan. 1997. Disponível em: <https://www.sciencedirect.com/science/article/pii/S0883902697849701>. Acesso em: 18 nov. 2016.

DEGEORGE, F.; ZECKHAUSER, R. The reverse LBO decision and firm performance: theory and evidence. The Journal of Finance, New York, v. 48, i. 4, p. 1323-1348, 1993. Disponível em: <https://ssl.lu.usi.ch/entityws/Allegati/pdf_ pub1269.pdf $>$. Acesso em: 25 jan. 2017.

EHRHARDT, M. C.; BRIGHAM, E. F. Administração financeira: teoria e prática. São Paulo: Cengage Learning, 2014.

FÁVERO, L. P.; BELFIORE, P.; DA SILVA, F. L.; CHAN, B. L. Análise de dados. Modelagem multivariada para tomada de decisões. Rio de Janeiro: Campus, 2009.

FORTUNA, E. Mercado financeiro: produtos e serviços. 15. ed. Rio de Janeiro: Qualitymark, 2008. 
GITMAN, L. J. Princípios de administração financeira. 10. ed. São Paulo: Pearson, 2004.

GROPPELLI, A. A.; NIKBAKHT, E. Administração financeira. 3. ed. São Paulo: Saraiva, 2010.

GUJARATI, D. N.; PORTER, D. C. Econometria Básica. 5. ed. Porto Alegre: Ed. AMGH, 2011.

HAIR JUNIOR, F. et al. Análise multivariada de dados. Porto Alegre: Bookman, 2009.

HOVAKIMIAN, A.; HUTTON, I. Merger Motivated IPOs. Financial Management, Tampa, v. 39, i. 4, p. 1547-1573, 2010.

ISLAM, Z. M. D.; AHMED, S. U.; HASAN, I. Corporate social responsibility and financial performance linkage: evidence from the banking sector of Bangladesh.

Journal of Organizational Management, George Town, v. 1, i. 1, p. 14-21, 2012.

JAIN, B. A.; KINI, O. The post issue operating performance of IPO firms. The journal of finance, v. 49, i. 5, p. 1699-1726, 1994. Disponível em: <https://www. jstor.org/stable/2329268>. Acesso em: 18 mar. 2017.

JENSEN, M. C.; MECKLING, W. H. Theory of the firm: managerial behavior, agency costs and ownership structure. Journal of Financial Economics, Lausanne, v. 3, i. 4, p. 305-360, 1976. Disponível em: <https://www.sciencedirect.com/science/ article/pii/0304405X7690026X>. Acesso em: 10 fev. 2017.

KHURSHED, A.; PALEARI, S.; VISMARA, S. The operating performance of initial public offerings: the UK experience. In: AUSTRALASIAN BANKING AND FINANCE CONFERENCE, 1., 2003, Sydney. Proceedins... Sydney: [s. n.], 2003.

KIM, K. A.; KITSABUNNARAT, P.; NOFSINGER, J. R. Ownership and operating performance in an emerging market: evidence from Thai IPO firms. Journal of Corporate Finance, Amsterdam, v. 10, i. 3, p. 355-381, 2004. Disponível em: <https://pdfs.semanticscholar.org/cd72/b13c6f81a7557aaf24238e005714f0ab2458.pdf>. Acesso em; 05 fev. 2017.

MATARAZZO, D. C. Análise financeira de balanços: abordagem gerencial. 7. ed. São Paulo: Atlas, 2010. 
MIKKELSON, W. H.; PARTCH, M. M.; SHAH, K. Ownership and operating performance of companies that go public. Journal of Financial Economics, Lausanne, v. 44, i. 3, p. 281-307, 1997. Disponível em: <http://lcb-file.uoregon.edu/wmikkels/ JFE\%20published\%20paper\%201997\%200wnership\%20and\%20operating\%20performance.pdf $>$. Acesso em: 12 mar. 2017.

PADOVEZE, C. L.; BENEDICTO, G. C. Análise das demonstrações financeiras. 3. ed., rev. e ampl. São Paulo: Cengage Learning, 2010.

PAGANO, M.; PANETTA, F.; ZINGALES, L. Why do companies go public? An empirical analysis. The Journal of Finance, New York, v. 53, i. 1, p. 27-64, 1998.

PINHEIRO, J. L. Mercado de capitais: fundamentos e técnicas. São Paulo: Atlas, 2007.

PROCIANOY, J. L.; SCHNORRENBERGER, A. A influência da estrutura de controle nas decisões de estrutura de capital das companhias brasileiras. Revista Brasileira de Economia, Rio de Janeiro, v. 58,n. 1, jan./mar. 2004. Disponível em: <http://www.scielo.br/scielo.php?script=sci_arttext\&pid=S0034-71402004000100006>. Acesso em: 25 jan. 2017.

ROSS, S. A.; WESTERFIELD, R. W.; JAFFE, J. F. Administração financeira. 10. ed. Porto Alegre: AMGH, 2015.

WARDIL, F. S. Análise do impacto das ofertas públicas iniciais sobre as empresas brasileiras: utilizando indicadores contábeis calculados a partir de evidências empíricas no Brasil. 2009. 57 p. Dissertação (Mestrado em Finanças e Economia)Fundação Getúlio Vargas, Rio de Janeiro, 2009.

WONG, J. Operating performance of initial public offering companies in Hong Kong. Journal of Modern Accounting and Auditing, New York, v. 8, i. 1, p. 4867, 2012.

ZILIO, A. Decisão das empresas de realizar um IPO e implicações sobre desempenho: uma análise da experiência brasileira. 2012. 55 p. Tese (Doutorado em Administração e Contabilidade)-Universidade de São Paulo, São Paulo, 2012. 


\section{Como citar este artigo:}

ABNT

KALIL, João Paulo Albuquerque; CARVALHO DE BENEDICTO, Gideon. Impactos da oferta pública inicial de ações no desempenho econômico-financeiro de empresas brasileiras na B3. RACE, Revista de Administração, Contabilidade e Economia, Joaçaba: Ed. Unoesc, v. 17, n. 1, p. 197-224, jan./abr. 2018. Disponível em: <http://editora.unoesc.edu.br/index.php/race>. Acesso em: dia/mês/ano.

\section{APA}

Kalil, J. P. A., \& Carvalho de Benedicto, G. (2018). Impactos da oferta pública inicial de ações no desempenho econômico-financeiro de empresas brasileiras na B3. RACE, Revista de Administração, Contabilidade e Economia, 17(1), 197-224. Recuperado em dia/mês/ano, de http://editora.unoesc.edu.br/index.php/race 